\title{
DIGITALCOMMONS
}

— @WAYNESTATE —

Wayne State University

Social Work Faculty Publications

Social Work

$3-5-2010$

\section{The child as held in the mind of the mother: The influence of prenatal maternal representations on parenting behaviors}

Carolyn Joy Dayton

Wayne State University, carolyn.dayton@wayne.edu

Alytia A. Levendosky

Michigan State University

William S. Davidson

Michigan State University

G. Anne Bogat

Michigan State University

\section{Recommended Citation}

Dayton, C. J., Levendosky, A. A., Davison, W. S., \& Bogat, G. A. (2010). The child as held in the mind of the mother: The influence of prenatal maternal representations on parenting behaviors. Infant Mental Health Journal 31(2), 220-241.

Available at: http://digitalcommons.wayne.edu/soc_work_pubs/45 
NOTICE IN COMPLIANCE WITH PUBLISHER POLICY: This is the peer reviewed version of the following article: Dayton, C. J., Levendosky, A. A., Davison, W. S., \& Bogat, G. A. (2010). The child as held in the mind of the mother: The influence of prenatal maternal representations on parenting behaviors. Infant Mental Health Journal 31(2), 220-241., which has been published in final form at http://dx.doi.org/10.1002/imhj.20253. This article may be used for non-commercial purposes in accordance with Wiley Terms and Conditions for self-archiving (http://olabout.wiley.com/WileyCDA/Section/id817011.html) 


\title{
The child as held in the mind of the mother: The influence of prenatal maternal representations on parenting behaviors
}

\author{
CAROLYN JOY DAYTON, Michigan State University \\ ALYTIA A. LEVENDOSKY, Michigan State University \\ WILLIAM S. DAVIDSON, Michigan State University \\ G. ANNE BOGAT, Michigan State University
}

\begin{abstract}
Using a longitudinal design, this study examined the relationship of a mother's prenatal representation of her child and her parenting behavior with that child at one-year-of-age in a sample of women who were either exposed or not exposed to intimate partner violence (IPV) $(\mathrm{n}=164$; mean child age $=1.1$ years, sd $=.11$ years; $52 \%$ male). Controlling for prenatal IPV, a MANCOVA analysis revealed that prenatal representational typology was significantly related to parenting behavior one year post-partum. Mothers whose representations were affectively deactivated (disengaged) were more behaviorally controlling with their children. Mothers whose representations were affectively overactivated (distorted) were more hostile with their children. Mothers with balanced representations demonstrated more positive parenting. Exposure to IPV did not moderate this relationship. There was no direct association between pre-natal or post-natal IPV and parenting behavior. These findings suggest that prenatal representations influence postnatal parenting behavior in significant and theoretically consistent ways and that this relationship functions similarly for both abused and non-abused women. Results add to the growing literature that internal representations serve to guide behavior throughout development and suggest that maternal working models may be one important link in the intergenerational transmission of attachment relationships.
\end{abstract}

Keywords internal representations, working models, parenting behavior, attachment theory, intimate partner violence (IPV), domestic violence

"I suggest, as you know I do, and I suppose everyone agrees, that ordinarily the woman enters into a phase, a phase from which she ordinarily recovers in the weeks and months after the baby's birth, in which to a large extent she is the baby and the baby is her. There is nothing mystical about this. After all, she was a baby once, and she has in her the memories of being a baby; she also has memories of being cared for, and these memories either help or hinder her in her own experiences as a mother."

Winnicott, 1966 (cited in Winnicott, 1987)

The importance of the parent-child relationship in infancy and early childhood as a primary contributor to child development has been wellestablished (Sameroff \& Emde, 1989). Theory and research suggest that the mother/child relationship begins when the mother is pregnant and that her prenatal internal representations influ- ence her postnatal internal representations as well as her postnatal relationship with her child (Bibring, Dwyer, Huntington, \& Valenstein, 1961; Stern, 1995; Zeanah \& Barton, 1989). However, little is known regarding whether prenatal representations predict later parenting behavior and whether contextual factors, such as intimate partner violence (IPV; defined here as male violence toward his female partner), are also influential. Trauma theory suggests that a woman's current experience of IPV will have important effects on her capacity to parent effectively (Herman, 1992). The present study examines the influence of prenatal maternal representations on later parenting behaviors and the moderating effect of IPV on this relationship in a heterogeneous-for-risk sample.

\section{Working Models: Representing Relationships and Guiding Behavior throughout Develop- ment}

Bowlby used the term "working model" to describe the process by which individuals construct 
and revise mental templates, or "representations," of their interpersonal environments (Bowlby, 1969/1982). He argued that these representations serve as guides within relationships; they facilitate the organization of incoming information, allowing the individual to choose from previously learned behavioral repertoires. By adulthood, working models that are based on the individual's early attachment experiences are thought to have been consolidated and assumed to be functioning in a relatively stable, consistent, and unconscious manner (Bowlby, 1969/1982; Collins $\&$ Read, 1994). In fact, research with adult populations has suggested a correspondence between early relationship history and later security within the context of adult romantic relationships (Mikulincer \& Shaver, 2003).

As adults make the transition into parenthood, they are required to make a critical shift from activation of the attachment behavioral system (which supports the goal of being protected) to activation of the caregiving behavioral system, which strives to be the provider of protection to the child (George \& Solomon, 1999) . As Aber, Belsky, Slade and Crnic (1999) explained, “... just as the motivation to seek care leads children to develop a representation of their relationship with their caregiver, so will the motivation to provide care lead parents to develop a representation of their relationship with their child" ( $p$. 1040).

This process begins during pregnancy when the majority of women enter into an intensely heightened phase of emotional preparedness for parenting (Cohen \& Slade, 2000). An inherent component of the maternal-fetal connection during pregnancy is the development of specific representations of the growing baby (Zeanah, Zeanah, \& Stewart, 1990). Following the birth of the infant, many other factors have been posited to influence the mother-infant relationship, and presumably the representation (Crockenberg \& Leerkes, 2000; Green, Coupland, \& Kitzinger, 1990). Thus, it is only through the assessment of prenatal maternal representations of the unborn infant that we can obtain an understanding of the mother's emotional connection to the infant that is still relatively unfettered by actual experiences.
Given the power of internal representations to guide behavior at an unconscious level, it is likely that prenatal representations have an effect on the ways in which a mother interacts with her newborn infant beginning with the first moments of contact. In fact, preliminary work in this area has provided confirmatory evidence that the mother's prenatal representations hold significant meaning for the developing mother-infant relationship (Benoit, Parker, \& Zeanah, 1997; HuthBocks, Levendosky, \& Bogat, 2002; Huth-Bocks, Levendosky, Theran, \& Bogat, 2004; Theran, Levendosky, Bogat, \& Huth-Bocks, 2005). To date, however, the majority of this research has examined the impact of prenatal working models on child attachment categories rather than on parenting behaviors.

The importance of a parent's ability to regulate his or her emotions and behaviors in order to facilitate the infant's healthy development has been well established in studies of early parenting (see Crockenberg \& Leerkes, 2000 for a review). Influenced by her own research as well as Bowlby's work (Bowlby, 1969/1982), Ainsworth's seminal study of infant attachment suggested that the mother's ability to tolerate a range of affective displays from her infant and not be overwhelmed or cut-off from them was key in her ability to provide sensitive caretaking (Ainsworth, Blehar, Waters, \& Wall, 1978). Stern's (1985) later synthesis of the theoretical work and empirical examinations of social-emotional development in infancy highlighted the importance of well-regulated, maternal parenting behaviors to the infant's early ability to internalize selfregulatory capacities. Consistent with these earlier works, Dix' (1991) comprehensive empirical review and formulation suggested that sensitive parenting is dependent on the parent's ability to provide an affectively organized response to the child's behaviors. He argued that parents who are able to regulate their emotions are better able to attend to the child's behaviors and then modify their own behaviors to meet the physical and emotional needs of the child. More recently, the growing neurobiological literature has shed light on the ways in which early, regulated, parentinfant interactions play a critical role in the in- 
fant's neurological development (see Fonagy, Gergely, Jurist, \& Target, 2004 for a synthesis of neurobiological, attachment and psychoanalytic theory). In a recent synthesis of this work, Schore (2003) states, "Infant research now suggests that the baby becomes attached to the modulating caregiver who expands opportunities for positive affect and minimizes negative affect" ( $p$. 8 ). This suggests that the parent must regulate his or her own affects and behaviors in order to have a modulating effect on the infant.

\section{Representing the Child: Structure and Con- tent}

Attachment theory suggests that a parent's ability to regulate his or her emotional and behavioral reactions within the parent-child relationship is dependent, in part, on the parent's internalized representation of that child. In the last two decades, research efforts have focused on examining parents' internal representations of relationships that are specific to individual children (Zeanah \& Barton, 1989; Zeanah, Benoit, Hirshberg, \& Barton, 1993). A number of research teams have developed comprehensive measures that yield an integrated picture of these representations (Aber, Slade, Berger, Bresgi, \& Kaplan, 1985; Bretherton, Biringen, Ridgeway, Maslin, \& Sherman, 1989; Zeanah et al., 1993). The Working Model of the Child Interview (WMCI, Zeanah et al., 1993), which is used in the present analyses, was designed for use in the prenatal and infancy periods and yields three typological categories that are distinct in their affective regulation styles (Balanced, and 2 Non-balanced types: Disengaged or Distorted). Grounded in attachment theory, this measure conceptualizes parental representations as reflecting a parent's relative ability to remain psychologically open and affectively regulated in response to the child's emotional expressions, physical and psychological needs, and individual personality characteristics (Zeanah, Benoit, Hirshberg, Barton, \& Regan, 1994). A mother holding a balanced representation of her child is accepting of the wide range of emotions (both positive and negative) that are experienced and expressed by her child, and she tends to describe a positive emotional connection with her child. A mother holding a disengaged representation, in contrast, exhibits a relational style with her child in which her affective involvement is deactivated. She perceives and describes her child in a rigid and often stereotyped manner which, while it may be idealized in nature, does not convey an authentic ability to be affectively open to the child's individual needs and personality development. A mother holding a distorted representation of her child is also unable to be open to the child's ongoing needs and experiences. Her relational style, however, represents an overactivated affective tie to the child that is characterized by a high level of emotional lability and an inability to focus on the actual personality characteristics of the child.

Using data from the longitudinal sample from which the current study is derived, Theran and colleagues (2005) examined the influence of the postnatal change or stability of working models over time (prenatal to post-natal) on post-natal parenting behaviors using a dichotomous model of representations (e.g., balanced vs. nonbalanced). They found that mothers who had demonstrated non-balanced representations prenatally, but whose representations shifted to balanced postnatally, were less likely to provide sensitive caregiving to their children than mothers who held balanced representations at both time points. In addition, mothers who initially held balanced representations, but later became non-balanced, were more sensitive in their postnatal parenting behaviors than women who held non-balanced representations at both time points. While this study highlights the importance of the influence of postnatal shifts in maternal representations in terms of balanced and non-balanced status on parenting behaviors, it does not explicate the ways in which distinct representational categories (e.g., balanced, disengaged, distorted) might differentially affect specific parenting behaviors. Given the significant differences in the emotion regulatory styles of the disengaged versus distorted groups, the implications of these differences as they manifest in parenting behaviors are an essential link that may further elucidate the intergenerational transmission of inter- 
nalized representations of relationships and help to guide recommendations for differential clinical interventions with mothers from the disengaged and distorted groups. In addition, Theran and colleagues (Theran et al., 2005) did not investigate the ways in which prenatal representations may be directly related to postnatal parenting behaviors. The current study investigates these relationships.

While there is a relative paucity of research linking prenatal representations with postnatal relationship quality, current research is beginning to document the influence of concurrentlyassessed parental (postnatal) representations of individual children on the parent-child relationship and parenting behaviors within these relationships (Benoit, Zeanah, Parker, Nicholson, \& Coolbear, 1997; Button, Pianta, \& Marvin, 2001; Coolbear \& Benoit, 1999; Sayre, Pianta, Marvin, $\&$ Saft, 2001). Although these studies do not explicate the causality of the relationship, they do begin to shed light on the nature of maternal representations of individual children as they manifest in a relational context. The current study extends these findings by more fully testing a causal link using longitudinal data.

\section{The Importance of Context: The Effect of IPV on Parenting}

Parental representations of children are likely to be influenced by environmental factors such as IPV, especially when these factors are salient during the formation of the representations. In fact, using the longitudinal dataset from which this sample is drawn, Huth-Bocks and colleagues found that exposure to IPV during pregnancy was associated with the prenatal balanced/nonbalanced status of a woman's internal working model of her child (Huth-Bocks et al., 2004). Specifically, they found that women who were experiencing IPV during pregnancy were more likely to develop non-balanced prenatal representations of their infants. This research did not examine, once the representation is formed, whether the presence of IPV during the period of early parenting moderated the relationship between maternal prenatal representations and later parenting behaviors.

Trauma theory predicts that exposure to IPV will result in a state of both emotional and cognitive hypervigilance on the part of the victim (Herman, 1992). Thus, exposure to IPV can be expected to influence a woman's functioning in many domains, including her parenting. Indeed, prior research has suggested that IPV has a negative influence on parenting behaviors (DeVoe \& Smith, 2002; Levendosky, Leahy, Bogat, Davidson, \& Von Eye, 2006; Levendosky, Lynch, \& Graham-Bermann, 2000). Parenting may be impaired because of the stress of experiencing IPV and its resultant negative effects on the mental health of the woman (Astin, Lawrence, \& Foy, 1993; Astin, Ogland Hand, Coleman, \& Foy, 1995; Vitanza, Vogel, \& Marshall, 1995). Exposure to IPV may inhibit a mother's ability to regulate her own affects and behaviors which may compromise her ability to engage in wellregulated interactions with her infant.

Prior research has examined the moderating effects of IPV on the relationship between psychosocial risk factors and parenting behaviors. For example, using observational assessments of parenting similar to those used in the current analysis, Ritchie and Holden (1998) predicted a moderating effect of IPV and found that parenting stress differentially affected the parenting behavior of women experiencing IPV compared to those who did not. That is, abused women demonstrated similar levels of physical affection (e.g., warmth) toward their children regardless of whether they were experiencing high or low levels of parenting stress whereas the parenting of non-abused women was negatively influenced by parenting stress. This suggests that potential psychosocial risk factors may operate differentially for abused and non-abused women. The current study examines the moderating effect of IPV on the relationship between prenatal maternal representations and later parenting behaviors.

\section{Hypotheses of Present Investigation}

The current study uses direct observation of parenting behaviors as the dependent variable (e.g., 
positive, controlling and hostile parenting). It was hypothesized that, controlling for prenatal IPV, a mother's prenatal internal representation would be related to her observed parenting behaviors of her one-year-old-child such that: 1) mothers holding balanced representations (e.g., affectively regulated and psychologically open) would display more positive parenting than mothers holding non-balanced representations, 2) mothers holding disengaged representations (e.g., affectively deactivated) would be more behaviorally controlling in their parenting than mothers in the other groups (e.g., in spite of their affective distance, they would push the child to behave in ways which matched their idealized vision of the child) and 3) mothers holding distorted representations (e.g., affectively overactivated and dysregulated) would exhibit higher levels of hostile parenting compared to mothers holding balanced or disengaged representations. In addition, it was hypothesized that postnatal exposure to IPV within the last year would moderate this relationship. The experience of postnatal IPV was predicted to override the protective effect of a balanced prenatal representation on later parenting behaviors for women experiencing IPV and to exacerbate the negative effects of each of the non-balanced representations.

\section{METHOD}

\section{Participants}

Participants of the current study were 164 women. They were a subsample of a larger, longitudinal study examining maternal and child risk and protective factors associated with exposure to IPV. Within this community-based sample, approximately half of the women reported experiencing IPV during pregnancy (Time 1) when they were initially enrolled in the study. Recruitment efforts were made to ensure an equal number of abused and non-abused pregnant women in the sample. Women who had been involved in a romantic relationship for at least six weeks during the pregnancy, were between the ages of 18 and 40 years, and who were able to speak and understand English well enough to complete the questionnaires and participate in the interviews were included in the study. Participants represented a range of cultural and ethnic groups. Sixty-two percent were Caucasian, 26\% were African-American, 5\% were Latina/Hispanic, $5 \%$ were Bi-racial, and $2 \%$ were other minority groups.

Time 2 data collection was conducted when the children were approximately one-year-of-age (mean age $=1.1$ years, $s d=.11$ years; range $=.92-1.8$ years; $52 \%$ males). At the Time 2 interview, 96 women reported that they had not experienced any IPV in the previous (e.g., postnatal) year and 68 women reported that they had experienced IPV. In addition, $43 \%$ of the sample were single women who had never been married, $45 \%$ were married, and $12 \%$ were separated or divorced. The average age of the mothers was 26.7 years $(s d=5.0)$. Participants represented a range of socio-economic groups. The sample is best described as heterogeneous-for-risk relative to SES. Monthly incomes ranged from \$267 to $\$ 9,733$ (median $=\$ 1,550 ; S D=\$ 1,665)$. This sample was very similar to and not statistically different from the demographic characteristics of the three-county region from which it was drawn.

Of the 42 women who participated in the Time 1 data collection, but not the Time 2, 6 refused further participation in the study, 10 could not be located, 13 were unable to complete the laboratory portion of the protocol, and 1 child had died. In addition 2 of the WMCI interviews and 10 of the videotaped sessions could not be coded due to technical difficulties in the recording process. There were no demographic differences (marital status, ethnicity, maternal age, level of education, monthly income, or exposure to IPV at the pregnancy interview) between the 42 participants from the ongoing longitudinal study whose data was not available for the present research and the 164 participants whose data was analyzed.

\section{Procedures}

Recruitment. Pregnant women were recruited through flyers posted at local agencies and clinics in a medium-sized, Midwestern city 
and the surrounding communities within a threecounty region. Please see Huth-Bocks (Huth Bocks, Levendosky, Bogat, \& Von Eye, 2004), for a more complete description of the recruitment procedures.

Time 1: Pregnancy Interview. When the woman was in her last trimester of pregnancy, the Time 1 interview was conducted in either the research office or in her home, according to her preference. Participants were informed about anonymity and confidentiality and provided their informed consent to participate (verbal and written). The representational interview (e.g., WMCI) was then administered by a trained research assistant. Interviews were audio-recorded and later transcribed. Women were paid for their participation at Time 1 as outlined in the informed consent.

Time 2: Mothers and their one-year olds. When their infants were 12 months old, mothers and infants were interviewed at project offices. Observations of mother-infant interaction behaviors were conducted at this time. Trained research assistants administered the representational interviews while the infants were assessed in a separate playroom. As outlined in the informed consent, women were paid and given a baby gift after completion of the Time 2 interview.

\section{Measures}

Maternal representation of the infant. The Working Model of the Child Interview (Zeanah et al., 1990) was used to assess the prenatal maternal representation at Time 1 . The WMCI is a semi-structured interview designed to capture a parent's internalized perceptions and subjective experience of her child's personality and her relationship with that child. In the present investigation the WMCI was modified for use in the third trimester of pregnancy by changing the wording of the interview from present to future tense. The validity and reliability of this interview has been demonstrated by Benoit and colleagues (1997) for use in the prenatal period. The WMCI required an average of one hour to ad- minister and interviews were audio-taped and transcribed for coding purposes. The coding scheme used in this investigation was drawn primarily from the system developed by Zeanah and colleagues (1993) for use with the WMCI. Percent agreement for typology classification was $96 \%$, yielding a kappa of .94 . The following is a brief description of each of the WMCI typological categories.

Balanced representations were typified by emotional warmth and acceptance. Parents scored in this category could imagine and describe being sensitively responsive to the needs of their infant. These parents had access to a range of emotionally well-regulated material concerning their infants. Disengaged representations were characterized by an emotional deactivation and distance from the infant. Descriptions of the infant were shallow and impoverished. Distorted representations reflected a pervasive distortion in the representation of the infant or the relationship with the infant. Narratives were incoherent, in the sense of providing confused, contradictory, or bizarre descriptions of the infant and the relationship. Descriptions of the infant and relationship were emotionally charged and dysregulated.

WMCI transcripts were coded using the system developed by the authors of this measure (Zeanah et al., 1993). Two graduate-level research assistants received specialized training from a consultant who had herself been trained and become reliable with the first author of the instrument/coding scheme. Representational classifications were rated using a categorical coding scheme (e.g., balanced, disengaged, distorted). Percent agreement for the two coders and Cohen's kappa analyses were used to assess inter-rater reliability for these data. Reliability analyses were completed on 26 interviews (13\% of the sample), some of which were double coded at periodic intervals to control for rater drift. Percent agreement for typology classification was $96 \%$, yielding a kappa value of .94 . Differences in typological classifications were resolved by conferencing, and the resulting consensus ratings and classifications were used in the analyses. The use of conferencing as a resolution technique 
has been established in the literature as bestpractice protocol in this field (Benoit, Parker et al., 1997).

Assessment of parenting behaviors. Four behavioral and two affective domains of maternal parenting behavior were assessed. The following 6 scales were used to code the observed maternal behavior: Sensitivity, Disengagement, Controlling Manipulation, Covert Hostility, Warmth, and Joy. All scales were scored using a five-point, interval, anchored rating system. Scales were designed such that higher scores reflected higher levels of that particular construct and were adapted from two primary sources: Ainsworth (Ainsworth \& Bell, 1974; Ainsworth, Bell, \& Stayton, 1971; Ainsworth et al., 1978) and Crittenden (1981). The Free Play segment lasted 12 minutes and was videotaped. However, only the last 10 minutes of the segment were used for coding purposes in order to allow the dyads time to get settled in the laboratory playroom. Mothers were instructed to, "Play with your baby for 12 minutes, in any way you like. If your baby needs a bottle or to have his/her diaper changed, you can do it at this time." The following is a brief description of each subscale.

Sensitivity reflected the mother's ability to perceive and accurately interpret the infant's signals and to respond to them in an attuned and well-regulated manner. Disengagement measured the degree to which the mother was disconnected from or lacked involvement with the baby and the play interaction. Controlling Manipulation measured the degree to which the mother's behavior interfered with rather than facilitated the infant's goals. Covert Hostility measured the degree to which the mother's communications to, and interactions with, the infant expressed covert hostility such as sarcastic comments, mocking the child, and teasing behaviors. Warmth measured the degree to which the mother expressed affection toward the infant in both her verbal and behavioral interactions. And, Joy measured the amount and quality of the mother's joyfulness during the interaction with the baby as evidenced by behaviors such as smiling, laughing, playing, and affective enthusiasm.
Reliability for the coding of videotapes was calculated using intraclass correlation coefficients. Based on a sub-group $(n=23)$ of data drawn from the entire sample, initial reliability ranged from .81 to .88 for the 6 maternal parenting codes. After establishing initial reliability, approximately $20 \%$ of the segments were chosen at random and double-coded. Final reliabilities reflect a combination of both the initial and ongoing reliability calculations and ranged from .81 to .83 for the six variables.

Assessment of IPV. The Severity of Violence Against Women Scales (SVAWS, Marshall, 1992) is a 46-item questionnaire designed to assess both violent behaviors and threats the woman has experienced from her partner. This measure was administered at Time 1 (pregnancy; used as a covariate in these analyses) and Time 2 (1 year post-partum). At Time 2 women reported IPV experienced by the current or most recent partner and, if applicable, by the partner who was prior to the most recent partner during the postpartum period. Examples of items include "destroyed something belonging to you," "punched you," and "demanded sex whether you wanted to or not." Respondents are instructed to rate their experiences of abuse on a 4-point scale ranging from "Never" to "Many Times." Items are individually coded from 0 (never) to 3 (many times) and summed. Marshall (1992) reported coefficient alphas among a community sample ranging from .86 to .96 for the subscales. Coefficient alphas for this sample were .95 for the Time 1 (pregnancy) partner, .96 for the Time 2 current or most recent partner and .99 for the Time 2 partner who was prior to the current or most recent partner.

\section{RESULTS}

Three primary sets of analyses in addition to descriptive information about the longitudinal distribution of IPV in this sample are presented. Initially, the dependent variable, which included 6 maternal parenting behaviors, was factor analyzed both for data-reduction purposes and as a response to the multi-collinearity present among 
these variables. Secondly, a MANCOVA analysis was conducted, controlling for prenatal IPV, to test the relationship between WMCI typology (Balanced: $n=86$; Disengaged: $n=46$; Distorted: $n=32$ ) and the 3 parenting factors. In addition, each of the univariate tests for the 3 parenting variables was also tested. Table 1 presents the descriptive data. Finally, a second MANCOVA analysis was conducted to test the hypothesis that IPV moderated the relationship between prenatal representations and parenting behaviors.
Table 1. Means and Standard Deviations of Parenting Factors by Representational Typology $(\bar{x}, s d)$.

\begin{tabular}{lccc}
\hline & Balanced & Distorted & Disengaged \\
\hline Positive Parenting & $3.3(0.84)^{\mathrm{a}}$ & $2.8(0.95)$ & $2.6(0.78)$ \\
Hostile Parenting & $1.6(1.00)$ & $2.4(1.50)^{\mathrm{b}}$ & $1.8(1.00)$ \\
Controlling Parenting & $2.3(1.40)$ & $2.7(1.50)$ & $3.0(1.40)^{\mathrm{c}}$ \\
\hline
\end{tabular}

a: balanced prenatal representations were associated more positive parenting than both the distorted and disengaged representations;

b: distorted representations were associated with more hostile parenting than balanced representations;

c: disengaged representations were associated with more controlling parenting than balanced representations;

Table 2. Rotated Factor Ratings of Maternal Interactive Behaviors*

\begin{tabular}{|c|c|c|c|c|c|}
\hline & & \multicolumn{4}{|c|}{ Factors } \\
\hline & & $\begin{array}{l}\text { Positive } \\
\text { Parenting }\end{array}$ & $\begin{array}{c}\text { Hostile } \\
\text { Parenting }\end{array}$ & $\begin{array}{l}\text { Controlling } \\
\text { Parenting }\end{array}$ & $\begin{array}{c}\text { Communalities } \\
\text { Extraction } \\
\text { (Initial set at 1.0) }\end{array}$ \\
\hline \multirow{8}{*}{$\begin{array}{l}\text { Maternal } \\
\text { Interactive } \\
\text { Behaviors }\end{array}$} & Sensitivity & 0.68 & -0.54 & -0.34 & 0.86 \\
\hline & Engagement & 0.77 & 0.00 & 0.39 & 0.75 \\
\hline & Controlling Manipulation & 0.01 & 0.21 & 0.95 & 0.95 \\
\hline & Covert Hostility & 0.00 & 0.97 & 0.15 & 0.96 \\
\hline & Warmth & 0.72 & -0.53 & -0.25 & 0.86 \\
\hline & Joy & 0.85 & 0.00 & 0.00 & 0.72 \\
\hline & Eigenvalue & 2.88 & 1.64 & 0.58 & \\
\hline & $\%$ Variance Explained & 47.90 & 27.30 & 9.70 & \\
\hline
\end{tabular}

${ }^{*}$ Items in bold are included in the factor scores.

\section{Factor Analysis of Maternal Interactive Be- haviors}

Correlations among the 6 maternal interactive variables were calculated and ranged from - .55 to .80 . An exploratory factor analysis was employed using a principal component analysis with varimax rotation (Table 2). Communalities ranged from .72 to .96 among the 6 parenting variables. Examination of the scree plot solution revealed 3 primary factors. Eigenvalues were $2.88,1.64$, and .58 for factors 1 through 3 , respectively. Factor 1 represented a positive parenting construct and included the disengagement (reverse-coded as engagement), joy, warmth and sensitivity variables. Scores for this factor were derived by standardizing the 4 original variables and then averaging the four standardized scale scores. Factor 2 represented a hostile parenting construct and included only the covert hostility variable. Similarly, factor 3 represented a controlling parenting construct and included only the controlling manipulation variable. Factors 2 and 3 were also standardized prior to analysis. Internal consistency for the positive parenting factor was measured using Cronbach's alpha and yielded a coefficient of .82 . Overall, the three factors accounted for $85 \%$ of the variance in the 6 original behavioral codes.

\section{Relation of Representational Typology and Maternal Interactive Behaviors: Multivariate Test}

A MANCOVA analysis was conducted, controlling for prenatal IPV, to test the relationship between WMCI typology (Balanced: $n=86$; Disengaged: $n=46$; Distorted: $n=32$ ) and the 3 parenting factors. Results were significant for the 
overall model $\left.\left[F(2,158)=6.46 ; \eta^{2}=.11 ; p<.05\right)\right]$ The pregnancy IPV covariate was not significant in the model $\left[F(2,158)=.07, \eta^{2}=.001 ; p=.98\right]$.

\section{Relation of Representational Typology and Maternal Interactive Behaviors: Univariate Tests}

Positive Parenting. The omnibus F was significant for positive parenting $[F(2,160)=$ 10.57; $\left.\eta^{2}=.12\right]$. A Bonferroni post-hoc analysis revealed that mothers with balanced representations displayed more positive parenting than mothers holding either disengaged or distorted representations $(\bar{x}$ balanced $=3.3, \bar{x}$ disengaged $=2.6, \bar{x}$ distorted $=2.8$ ). However, no differences were found in positive parenting between the distorted and disengaged groups.

Hostile Parenting. This test was also significant $\left[F(2,160)=5.68 ; \eta^{2}=.07\right]$. A Bonferroni post-hoc analysis revealed that mothers with distorted representations displayed higher levels of hostile parenting than mothers holding balanced representations ( $\bar{x}$ balanced $=1.6, \bar{x}$ distorted $=2.4$ ). Additionally, there was a trend in the data suggesting that mothers holding distorted representations tended to display higher levels of hostile parenting when compared to those holding disengaged representations ( $\bar{x}$ disengaged $=1.8, \mathrm{p}=.09$ ). No differences were found between the balanced and disengaged groups.

Controlling Parenting. This test was also significant $\left[F(2,160)=3.84 ; \eta^{2}=.05\right]$. A Bonferroni post-hoc analysis revealed that mothers with disengaged representations displayed higher levels of controlling parenting than mothers holding balanced representations $(\bar{x}$ balanced $=$ $2.3, \bar{x}$ disengaged $=3.0$ ). No differences were found, however, between the balanced and distorted or between the distorted and disengaged groups.

\section{Distribution of IPV}

The distribution of IPV exposure by WMCI category and the longitudinal stability of IPV expo- sure across data collection waves are presented in Tables 3 and 4, respectively. As Table 3 makes clear, approximately half of the women within the balanced group reported IPV exposure during pregnancy. In comparison, approximately three quarters of the women in the non-balanced groups (e.g., distorted and disengaged) reported prenatal IPV exposure. During the postnatal period (Time 2), the percentages of IPV exposure dropped for all 3 WMCI groups. An examination of Table 4 reveals that almost three quarters of the women maintained their IPV status from pregnancy to one year postpartum: $35 \%$ of women did not endorse IPV at either time period and $36 \%$ of women endorsed IPV at both time periods. In addition, $23 \%$ of the women who endorsed IPV during pregnancy were not exposed to abuse during the first year of their child's life, and $6 \%$ of women experienced IPV postnatally despite reporting no abuse during pregnancy.

\section{MANCOVA Analysis Examining IPV as a Moderating Variable}

Initially, controlling for prenatal IPV, postnatal IPV (measured dichotomously: abuse vs. no abuse) was examined as a main effect on the 3 parenting factors in a MANCOVA analysis and was not significant, although there was a trend toward significance $[F(3,158)=2.61 ; p=.054]$. Subsequently, in order to test the hypothesis that postnatal IPV may moderate the relationship between representational typology and parenting factors, a MANCOVA analysis was conducted with prenatal IPV entered as a covariate. A continuous postnatal IPV variable was used in this analysis to create the interaction term. Thus, the interaction included the representational typology variable and the postnatal IPV variable (Baron \& Kenny, 1986). The dependent variables included the 3 parenting factors: positive, hostile and controlling parenting. Results indicated that IPV status did not moderate the relationship between representational typology and parenting behaviors in this sample $[F(3,158)=1.82 ; p$ $=.15]$. 
Table 3. Prenatal and Postnatal IPV exposure by Prenatal WMCI category.

\begin{tabular}{|c|c|c|c|c|c|c|c|c|c|}
\hline \multirow{3}{*}{ Prenatal WMCI Typology } & \multirow{3}{*}{$n$} & \multicolumn{4}{|c|}{$\begin{array}{l}\text { \% of women endorsing } \\
\text { Prenatal IPV Exposure }\end{array}$} & \multicolumn{4}{|c|}{$\begin{array}{l}\text { \% of women endorsing } \\
\text { Postnatal IPV Exposure }\end{array}$} \\
\hline & & \multicolumn{2}{|c|}{ Exposure } & \multicolumn{2}{|c|}{ No Exposure } & \multicolumn{2}{|c|}{ Exposure } & \multicolumn{2}{|c|}{ No Exposure } \\
\hline & & $\%$ & $n$ & $\%$ & $n$ & $\%$ & $n$ & $\%$ & $n$ \\
\hline Balanced & 86 & $47 \%$ & 40 & $53 \%$ & 46 & $37 \%$ & 32 & $63 \%$ & 54 \\
\hline Disengaged & 46 & $74 \%$ & 34 & $26 \%$ & 12 & $48 \%$ & 22 & $52 \%$ & 24 \\
\hline Distorted & 32 & $72 \%$ & 23 & $28 \%$ & 9 & $44 \%$ & 14 & $56 \%$ & 18 \\
\hline Total & 164 & $59 \%$ & 97 & $41 \%$ & 67 & $42 \%$ & 68 & $58 \%$ & 96 \\
\hline
\end{tabular}

Table 4. Change status in IPV from T1 (pregnancy) to T2 (postnatal year).

T1: Pregnancy IPV

\begin{tabular}{|cccc|}
\hline \multicolumn{2}{c}{ IPV Not Exposed } & \multicolumn{2}{c|}{ IPV Exposed } \\
$\%$ & $n$ & $\%$ & $n$ \\
\hline $35 \%$ & 58 & $23 \%$ & 38 \\
$6 \%$ & 9 & $36 \%$ & 59 \\
\hline
\end{tabular}

Table 5. Means and Standard Deviations of Postnatal Parenting Factors by Prenatal and Postnatal IPV exposure $(\bar{x}, s d)$.

\begin{tabular}{lcccc} 
& \multicolumn{2}{c}{ Prenatal IPV Exposure Status } & \multicolumn{2}{c}{ Postnatal IPV Exposure Status } \\
\cline { 2 - 5 } & Exposure $(n=97)$ & No Exposure $(n=67)$ & Exposure $(n=68)$ & No Exposure $(n=96)$ \\
\hline Positive Parenting & $2.94(0.91)$ & $3.16(0.88)$ & $2.83(0.87)$ & $3.17(0.91)$ \\
Hostile Parenting & $1.91(1.20)$ & $1.72(1.10)$ & $2.04(1.23)$ & $1.68(1.09)$ \\
Controlling Parenting & $2.70(1.40)$ & $2.36(1.43)$ & $2.81(1.47)$ & $2.39(1.36)$ \\
\hline
\end{tabular}

\section{DISCUSSION}

This study examined the influence of both intrapsychic (prenatal maternal representations) and exogenous (postnatal exposure to IPV) factors on a mother's parenting behaviors with her oneyear-old child. Controlling for prenatal exposure to IPV, maternal representations were significantly related to observer-rated maternal interactions in theoretically consistent ways. That is, the mother's affective regulation style, as it manifested in her representation of her unborn baby, was concordant with her behavioral style when interacting with that child one year after birth. The specificity of this finding has not been ex- amined previously in the literature and provides empirical support for the attachment theory premise that internal relationship representations function to guide behaviors within relationships. Our findings suggest that maternal working models that are formed prior to the birth of the baby may be one important link in the intergenerational transmission of attachment relationships.

In addition, controlling for prenatal IPV, there was no main effect for postnatal IPV on observed parenting, and postnatal IPV did not moderate the relationship between prenatal representations and parenting behaviors. That is, prenatal representations were related to later par- 
enting behavior in similar ways for both abused and non-abused women.

\section{Prenatal Representations and Observed Par- enting in Infancy}

Our findings are consistent with the attachment literature on internal working models of relationships which argues that a mother's internalized representation of her child will influence her parenting behaviors with that child. Attachment theory posits that, in the optimal case, internalized representations allow the individual to experience and process emotionally salient information within relationships (secure, balanced). Alternatively, sub-optimal representations either restrict access to affective processing (avoidant, disengaged) or they preference a heightened attention to and dysregulation of these affects (ambivalent, distorted) within relationships. Attachment studies in infancy highlight the behavioral manifestations of these relationship representations (Cassidy, 1999). Similarly, prior meta-analyses have demonstrated that a mother's internal representations of her own childhood attachment relationships are related to her parenting behaviors with her children (Van IJzendoorn, 1995). To date, however, the distinct parental affective regulatory style as it manifests in the representation of a specific child has not been empirically examined with respect to the parent's subsequent parenting behaviors with that child. This is the first study to examine this relationship prenatally at the typological level of analysis. In addition, the current investigation examined this relationship in a group of women, approximately half of whom had experienced IPV at the time of recruitment into the study.

Although unique in terms of the sample and methodological design, the current findings are consistent with the extant literature linking concurrently assessed maternal representations of infants and older children with maternal parenting behaviors (Aber et al., 1999; Button et al., 2001; Sayre et al., 2001; Slade, Belsky, Aber, \& Phelps, 1999). In addition, our findings are broadly consistent with longitudinal work done by Slade and colleagues (1999) who studied postnatal parenting data with the mothers of children in the second year of life. These investigators found that mothers demonstrating positive and well-regulated postnatal representations of their children (e.g., higher scores on the Joy/Pleasure/Coherence factor of the PDI) exhibited higher levels of positive parenting with them. In addition, mothers with postnatal representations high in the expression of anger demonstrated lower levels of positive parenting behaviors with their children.

The present study utilized clinically rich interview and observation methodology that tap relationship salient regulation capacities. The representational interviews utilized in this study were semi-structured in design and asked mothers to explore and reflect on their thoughts and feelings about their relationship with their unborn baby. Similarly, observations of motherchild interactions allowed mothers to interact with their infants in a semi-structured environment where a set of standardized toys was available but no restrictions were placed on whether or how the mothers played with their babies. Our analysis of both of these protocols allowed us to examine clinically salient information using methods that are similar to the clinical interview and mother-child interaction observations used by infant mental health clinicians working in both home-visit and center-based settings.

Balanced Representations. Internal representation in our study was defined and coded such that pregnant mothers holding balanced representations of their infants described themselves as being open to a range of behaviors and emotional reactions in their babies. Given these representational characteristics, our finding that mothers in the balanced group tended to exhibit higher levels of positive parenting behaviors is both theoretically consistent and intuitively clear. In these analyses, positive parenting is defined as parenting that is warm, sensitive, joyful, and engaged. By definition, balanced representations, unlike disengaged and distorted representations, allow for an open and flexible conceptualization of the child. It is this flexibility that allows a parent to be attuned to the genuine emotions and behaviors 
of the child and then to react behaviorally in a manner that is consistent with what the child needs at that moment.

For example, one mother in the present study (26 years of age) who held a balanced prenatal representation of her child was asked during the prenatal interview how she would feel when her baby became upset, and she responded, "I don't think it will bother me. You know, I won't want my baby to be upset, and I'm going to do what I can to figure out why and remedy the problem, but as far as upsetting me, I don't think that will happen." This mother's representational narrative suggests that she could both access and tolerate her infant's upset behaviors without becoming affectively dysregulated herself. This mother reported minimal IPV exposure during her pregnancy (SVAWS score $=5$ ), followed by significant exposure to IPV during the year after her child was born (SVAWS score $=48$ ). Despite her postnatal violence exposure, however, at the postnatal freeplay session she exhibited high levels of positive parenting with her child (13 months of age). Specifically, on the 5-point factor scores (where 1 indicates no evidence of the behavior and 5 indicates high levels of the behavior), her positive parenting factor score was 4.25. In addition, she demonstrated moderate levels of controlling parenting (factor score $=3$ ) and no evidence of hostile parenting (factor score $=1)$.

Distorted Representations. The second finding from the current study was that mothers holding distorted representations of their children prenatally demonstrated increased levels of hostility and anger in their interactions with them compared to mothers in the balanced group. In addition, there was a trend in these data such that mothers in the distorted group were more likely to display hostile parenting when compared to mothers in the disengaged group. It is possible that with a larger sample size this finding may have reached a level of statistical significance. Unlike mothers in the balanced and disengaged groups, the narratives of women holding distorted representations often gave the impression that the child's real self was lost in the storm of the mother's emotions; at times it was the lightning rod that inadvertently attracted the mother's powerful emotional energy. Thus, dysregulated emotional activation and anger, which was often a salient feature of the narratives of mothers in this group, was also evident in their subsequent behavioral interactions with their children. Mothers holding distorted representations described an affectively charged and dysregulated emotional connection with their child, often characterized by a distortion such as a rolereversal of the parent-child relationship.

For instance when asked during the prenatal interview about how she would feel when her baby became upset, a mother (29 years of age) in the distorted category responded: "I'd probably sit and hold it, rock it. . . like my kids right now, if I get where I'm depressed or something, I'll just tell them I need a hug. . . just sit there, hold it, rock back and forth, you know. Just to feel close and feel secure. You know, adults need that, too. Um, it just makes me feel good, knowing that, you know, my kids are there for me. . ." This mother's prenatal representation of her child appears to be role reversed in that she is expecting her baby to care for her own emotional needs. In fact, her first association is to her own upset feelings, rather than those of her baby, with the stated expectation that her baby will make her feel better when she is upset. This mother reported that she was exposed to IPV during her pregnancy (SVAWS score $=20$ ), but not during the first year of her child's life. At the postnatal freeplay session, when her child was 13.5 months of age, she demonstrated high levels of hostile parenting (factor score $=5$ ) and moderate levels of positive parenting (factor score $=3.75$ ) and controlling parenting (factor score $=3$ ).

A specific example of hostile parenting behaviors involves another mother who, when her child became somewhat upset during the freeplay segment, pinned her child's arms to the floor and, putting her face just above his, said in an enraged voice, "You think you can hurt me? You can't hurt me." Like the mother quoted above, this mother also appears to have a distorted representation of her child. While the first mother's representational distortion involves placing her baby 
in the role of caretaker of her own needs, the second mother's distortion places her baby in the role of the assailant.

\section{Disengaged Representations. Finally, our} results indicated that mothers holding prenatal disengaged representations of their infants tended subsequently to be more controlling with them as compared to mothers holding balanced representations. In other words, mothers who were emotionally disengaged and deactivated in terms of their representation of their infant tended to be behaviorally overly engaged (e.g., controlling) with them. While this finding seems counterintuitive, it is, in fact, theoretically consistent. That is, mothers who earned high scores on the controlling parenting factor tended to take more of a teaching stance when interacting with their infants. They frequently spent a good deal of time showing their child how to "correctly" use the toys in the playroom and were relatively unwilling to follow the child's lead in play. Thus, while they were clearly behaviorally engaged with their children, these mothers did not evince high levels of emotional engagement and, in fact, did not seem to be attuned to the desires and needs of their children in this unstructured play session. Consistent with their emotional deactivation and affective "overcontrol" within their representations, these women exhibited a high level of behavioral control with their infants.

Mothers holding disengaged representations tended to describe their infants in emotionally impoverished and affectively deactivated ways during the representational interview. For example, responding to the question during the prenatal interview that asked what she thought she would do when her baby became upset, one mother (24 years of age) in this category responded, '[I'll] just deal with it. Just like, 'all right, I see you have attitude today'. All I'll say [is], 'today's the day for the attitude' (laughs)." In this case, the mother's response represents an emotionally deactivated style as well as a sense that she is not affectively connected to her unborn infant. This mother reported IPV exposure during her pregnancy (prenatal SVAWS score = 12), followed by minimal exposure during the first year of her child's life (postnatal SVAWS score $=2$ ). Her parenting with her child (13 months of age) was characterized by high levels of controlling behaviors (factor score $=5$ ), moderate levels of positive parenting (factor score = 3.5 ) and low levels of covert behaviors (factor score $=2$ ).

A specific example of controlling behavior was evident in multiple mother-infant dyads during the freeplay session. One of the toys in the playroom was a shape-sorter with geometric shaped holes at the top of a canister and three dimensional shapes designed to fit into the corresponding holes. Mothers high on positive parenting were likely to allow their children to play with this toy in any way they desired, including allowing them to 'cheat' by taking off the top of the canister and dumping the shapes in. Mothers who were high on controlling behaviors, however, frequently held down the top of the canister with one hand and physically manipulated the child's hand such that the shapes all landed in their correct holes. In many cases, these controlling behaviors were sustained even in the face of emotional upset on the part of the child. The mother's unstated agenda seemed to be that the rules of the game must be maintained at all costs, even in the face of "attitude" on the part of the baby.

\section{IPV and Parenting}

Contrary to our hypotheses, postnatal IPV did not moderate the relationship between prenatal maternal representations and observed parenting. In addition, there was no main effect of postnatal IPV on parenting behaviors and the prenatal IPV covariate was not significant in the model. Thus, internal representations functioned similarly for the abused and non-abused groups of women. These findings suggest that internal representations may play a significant role in guiding parenting behaviors even in the context of IPV. Whereas trauma theory would predict that a woman's internal resources for ego-resiliency and self regulation would be overwhelmed by the experience of the abuse, it may be that her representation of her child is powerful enough such 
that even in the face of subsequent (postnatal) IPV it continues to have a significant impact on her parenting.

Alternatively, it is possible that IPV exposure is less important in predicting parenting outcomes than subsequent trauma symptoms that some of the abused women may subsequently develop. The fact that trauma symptoms were not included in the current study is clearly a limitation. However, the finding that representations impact parenting differentially within the two non-balanced types suggests that representations are driving some of the variance of the parenting variables, despite the possible contribution of trauma symptoms.

In another study using data from the larger longitudinal study from which the current study is derived, an SEM analysis revealed that postnatal IPV did predict postnatal parenting, whereas prenatal IPV did not (Levendosky, Leahy, Bogat Davidson, \& Von Eye, 2006). However, in contrast to the current paper, this study examined parenting behavior as a mediator along with maternal mental health in predicting children's outcomes. In addition, this model did not include maternal prenatal representations. Thus, based on the current findings, it appears that postnatal IPV does not directly predict to postnatal parenting behaviors when other contextual variables, such as maternal mental health and social support, are not accounted for.

It is possible that the experience of IPV is most powerful in the formation of representations during pregnancy. This explanation is supported by attachment theory which emphasizes the powerful influence that internal working models, once developed, have on subsequent human behavior (Bowlby, 1969/1982). In fact, in a cross-sectional analysis using data from the larger longitudinal study, Huth-Bocks and colleagues (2004) found that women who reported prenatal exposure to IPV were more likely to hold non-balanced prenatal representations (e.g., either disengaged or distorted) of their infants. Thus, it may be that exposure to IPV is most critical in terms of its influence on the formation of the representation itself, rather than directly influencing parenting behaviors. Once formed, in- ternal representations appear to drive maternal behavior regardless of whether the woman experiences postnatal violence.

Finally, there were important methodological issues that may have influenced these results. Specifically, this was a community sample of women reporting various levels of IPV. It is possible that, whereas the relatively lower levels of IPV experienced by the women in a community sample does not moderate the relationship between prenatal representations and parenting behaviors, extreme levels of abuse that are commonly present in shelter samples may in fact prove to be a significant moderator. It is also clearly the case that the violence experienced by these women changes over time and may not best be viewed as a static variable, even within a oneyear period (Bogat, Levendosky, Theran, von Eye, \& Davidson, 2003). Our assessment of IPV asked women to report their exposure over the course of the one-year postnatal period. Thus, we were not able to determine recency of abuse within this period. It is possible that the parenting behaviors of women with more recent abuse (e.g., a week before the assessment of parenting) were more impaired than the parenting behavior of women with more distal abuse (e.g., 10 months before the parenting assessment). This is a further limitation of this study.

In addition, the observational data included in these analyses were collected in a laboratory setting and not in the family's home environment. While this methodology is consistent with other research examining these constructs (Donovan, Leavitt, Taylor, \& Broder, 2007), the demand characteristics of the setting itself may have been a factor in the mother's and child's behaviors. That is, it is possible that some mothers and children felt uncomfortable in this unfamiliar setting and that their behaviors when interacting with each other were impacted as a result. The balance between standardization of procedures and naturalistic observation is always an issue in this type of research. In the current study, the risk to the participants of obtaining observational data in many homes where IPV was occurring precluded the ability to obtain naturalistic data. 


\section{Summary}

Examinations of the influence of parental state of mind with respect to his or her past attachment history on parenting behaviors have been well established (Van IJzendoorn, 1995). To date, however, there have been few published studies that examine prenatal maternal representations and their relationships to later observed parenting behaviors. Theran and colleagues (Theran et al., 2005) examined the influence of postnatal shifts in representations over time using a dichotomous variable (e.g., balanced versus non-balanced), on parenting behaviors. To our knowledge, however, no studies have examined the direct influence of prenatal maternal representations at the typological level on later parenting behaviors. Our results suggest that this distinction is critical; we found that the regulation style that was manifest in the mother's prenatal working model (e.g., balanced, disengaged, distorted) was significantly related to her behavioral regulation style (e.g., sensitive, controlling, hostile) with her one-year-old child. Contrary to our predictions, these results were similar for both the postnatally abused and nonabused groups of women, suggesting that representations drive behavior in similar and important ways despite the presence of maternal postnatal exposure to violence.

While the data reported here are correlational in nature and cannot reveal underlying causal relationships, the fact that the maternal representation was measured during pregnancy and thus prior to the mother having any actual interactions with the infant lends support to the hypothesis that there may be a causal relationship in this process. Thus, these results are theoretically consistent and add to the growing literature that internal representations serve to guide behavior throughout development. The finding that prenatal representations directly affect later observed parenting behaviors suggests that maternal working models may be one important link in the intergenerational transmission of attachment relationships.

\section{Clinical and Policy Implications}

The findings from this study are relevant both to clinical work and public policy related to the families of young children. Women form representations of their infant children during pregnancy and these early representations are related to their behavior with those children one year later in both higher risk (e.g., IPV exposed) and lower risk groups. Thus, it seems especially important that professionals working in the early intervention field understand this important window of time in the life of a mother and strive to intervene with pregnant women who show signs of relationship difficulties with their infants prior to the birth of those infants (e.g., mothers who seem disengaged or distorted with respect to their developing relationship with their unborn infants).

At the policy level this might be achieved by funding mental health professionals to work collaboratively with obstetricians to identify and treat such women. This would necessitate the development of screening tools which could be based, in part, on the WMCI. Clinical interventions could then be differentially tailored to address the underlying deficits for the distorted and disengaged groups. For example, clinical interventions for mothers holding distorted prenatal representations of their infants may include helping them to better regulate their affective relationship with their infant using parent-infant psychotherapy techniques. In contrast, mothers holding prenatal disengaged representations could be helped to access and process their affects such that a more emotionally connected relationship with their infant becomes possible. In either case, an understanding of the mother's emotion regulation style as it manifests in her internal representation of her infant will enhance the ability of the infant mental health specialist to intervene effectively with women who are at-risk for parentinfant relationship disturbances. 


\section{REFERENCES}

Aber, J. L., Belsky, J., Slade, A., \& Crnic, K. (1999). Stability and change in mothers' representations of their relationship with their toddlers. Developmental Psychology, 35(4), 1038-1047.

Aber, J. L., Slade, A., Berger, B., Bresgi, I., \& Kaplan, M. (1985). The Parent Development Interview. Unpublished Manuscript.

Ainsworth, M. D. S., \& Bell, S. M. (1974). Mother-infant interaction and the development of competence. In K. Connolly \& J. Bruner (Eds.), The growth of competence (pp. 97-118). New York: Academic Press.

Ainsworth, M. D. S., Bell, S. M., \& Stayton, D. J. (1971). Attachment and exploratory behavior of one year olds. In H. R. Schaffer (Ed.), The origins of human social relations (pp. 17-52). New York: Academic Press.

Ainsworth, M. D. S., Blehar, M. C., Waters, E., \& Wall, S. (1978). Patterns of attachment: A psychological study of the strange situation. Oxford, England: Lawrence Erlbaum.

Astin, M. C., Lawrence, K. J., \& Foy, D. W. (1993). Posttraumatic stress disorder among battered women: Risk and resiliency factors. Violence and Victims, 8(1), 17-28.

Astin, M. C., Ogland Hand, S. M., Coleman, E. M., \& Foy, D. W. (1995). Posttraumatic stress disorder and childhood abuse in battered women: Comparisons with maritally distressed women. Journal of Consulting and Clinical Psychology, 63(2), 308-312.

Baron, R. M., \& Kenny, D. A. (1986). The moderatormediator variable distinction in social psychological research: Conceptual, strategic, and statistical considerations. Journal of Personality and Social Psychology, 51, 11731182.

Benoit, D., Parker, K. C. H., \& Zeanah, C. H. (1997). Mothers' representations of their infants assessed prenatally: Stability and association with infants' attachment classifications. Journal of Child Psychology \& Psychiatry \& Allied Disciplines, 38(3), 307-313.

Benoit, D., Zeanah, C. H., Parker, K. C. H., Nicholson, E., \& Coolbear, J. (1997). "Working Model of the Child Interview": Infant clinical status related to maternal perceptions. Infant Mental Health Journal, 18(1), 107-121.

Bibring, G. L., Dwyer, T. F., Huntington, D. S., \& Valenstein, A. F. (1961). A study of the psychological processes in pregnancy and of the earliest mother-child relationship. Psychoanalytic Study of the Child, 16, 9-72.
Bogat, G. A., Levendosky, A. A., Theran, S. A., von Eye, A., \& Davidson, W. S. (2003). Predicting the Psychosocial Effects of Interpersonal Partner Violence (IPV) How Much Does a Woman's History of IPV Matter? Journal of Interpersonal Violence, 18(11), 1271-1291.

Bowlby, J. (1969/1982). Attachment and loss, Vol. 1: Attachment (2nd ed.). New York: Basic Books.

Bretherton, I., Biringen, Z., Ridgeway, D., Maslin, C., \& Sherman, M. (1989). Attachment: The parental perspective. Infant Mental Health Journal, 10(3), 203-221.

Button, S., Pianta, R. C., \& Marvin, R. S. (2001). Mothers' representations of relationships with their children: Relations with parenting behavior, mother characteristics, and child disability status. Social Development, 10(4), 455-472.

Cassidy, J. (1999). The nature of the child's ties. In J. Cassidy \& P. Shaver (Eds.), Handbook of Attachment: Theory, Research and Clinical Applications (pp. 3-20). New York: Guilford Press.

Cohen, L. J., \& Slade, A. (2000). The psychology and psychopathology of pregnancy: Reorganization and transformation. In C. H. Zeanah (Ed.), Handbook of Infant Mental Health. New York: The Guilford Press.

Collins, N. L., \& Read, S. J. (1994). Cognitive representations of attachment: The structure and function of working models. In K. Bartholomew \& D. Perlman (Eds.), Attachment Processes in Adulthood (pp. 53-90). Bristol, PA: Jessica Kingsley Publishers.

Coolbear, J., \& Benoit, D. (1999). Failure to thrive: Risk for clinical disturbance of attachment? Infant Mental Health Journal, 20(1), 87-104.

Crittenden, P. M. (1981). Abusing, neglecting, problematic, and adequate dyads: Differentiating by patterns of interaction. Merrill Palmer Quarterly, 27(3), 201-218.

Crockenberg, S., \& Leerkes, E. (2000). Infant social and emotional development in family context. In C. H. Zeanah (Ed.), Handbook of Infant Mental Health (2nd ed., pp. 6090). New York: The Guilford Press.

DeVoe, E. R., \& Smith, E. L. (2002). The impact of domestic violence on urban preschool children: Battered mothers' perspectives. Journal of Interpersonal Violence, 17(10), 1075-1101.

Dix, T. (1991). The affective organization of parenting: Adaptive and Maladaptive Process. Psychological Bulletin, 110(1), 3-25. 
Donovan, W., Leavitt, L., Taylor, N., \& Broder, J. (2007). Maternal sensory sensitivity, mother-infant 9-month interaction, infant attachment status: Predictors of mothertoddler interaction at 24 months. Infant behavior and development, 30, 336-352.

Fonagy, P., Gergely, G., Jurist, E., \& Target, M. (2004). Affect Regulation, Mentalization, and the Development of the Self. New York: Other Press.

George, C., \& Solomon, J. (1999). Attachment and caregiving: The caregiving behavioral system. In J. Cassidy \& P. R. Shaver (Eds.), Handbook of attachment: Theory, research, and clinical applications (pp. 649-670). New York: The Guilford Press.

Green, J. M., Coupland, V. A., \& Kitzinger, J. V . (1990). Expectations, experiences, and psychological outcomes of childbirth: A prospective study of 825 women. Birth, 17(1), 15-24.

Herman, J. L. (1992). Trauma and recovery. New York: Basic Books.

Huth-Bocks, A. C., Levendosky, A. A., \& Bogat, G. A. (2002). The effects of domestic violence during pregnancy on maternal and infant health. Violence and Victims, 17, 169-185.

Huth-Bocks, A. C., Levendosky, A. A., Theran, S. A., \& Bogat, G. A. (2004). The impact of domestic violence on mothers' prenatal representations of their infants. Infant Mental Health Journal, 25(2), 79-98.

Huth Bocks, A. C., Levendosky, A. A., Bogat, G. A., \& Von Eye, A. (2004). The Impact of Maternal Characteristics and Contextual Variables on Infant-Mother Attachment. Child Development, 75(2), 480-496.

Levendosky, A. A., Leahy, K. L., Bogat, G. A., Davidson, W. S., \& Von Eye, A. (2006). Domestic Violence, Maternal Parenting, Maternal Mental Health, and Infant Externalizing Behavior. Journal of Family Psychology, 20(4), 544-552.

Levendosky, A. A., Leahy, K. L., Bogat , G. A., Davidson, W. S., \& Von Eye, A. (2006). Domestic Violence, Maternal Parenting, Maternal Mental Health, and Infant Externalizing Behavior. Journal of Family Psychology, 20(4), 544-552.

Levendosky, A. A., Lynch, S. L., \& Graham-Bermann, S. A. (2000). Mothers' perceptions of the impact of woman abuse on their parenting. Violence Against Women, 6(3), 247-271.
Marshall, L. L. (1992). Development of the Severity of Violence Against Women Scales. Journal of Family Violence, 7(2), 103-121.

Mikulincer, M., \& Shaver, P. R. (2003). The attachment behavioral system in adulthood: Activation, psychodynamics, and interpersonal processes. In M. P. Zanna (Ed.), Advances in experimental social psychology (Vol. 35, pp. 53152). San Diego, CA: Academic Press.

Ritchie, K. L., \& Holden, G. W. (1998). Parenting stress in low income battered and community women: Effects on parenting behavior. Early Education and Development, 9(1), 97-112.

Sameroff, A. J., \& Emde, R. N. (Eds.). (1989). Relationship disturbances in early childhood: A developmental approach. New York: Basic Books.

Sayre, J. M., Pianta, R. C., Marvin, R. S., \& Saft, E. W. (2001). Mothers' representations of relationships with their children: Relations with mother characteristics and feeding sensitivity. Journal of Pediatric Psychology, 26(6), 375384 .

Schore, A. N. (2003). Affect Dysregulation and Disorders of the Self. New York: W. W. Norton \& Company, Inc.

Slade, A., Belsky, J., Aber, J. L., \& Phelps, J. L. (1999). Mothers' representations of their relationships with their toddlers: Links to adult attachment and observed mothering. Developmental Psychology, 35(3), 611-619.

Stern, D. N. (1985). The Interpersonal World of the Infant: A View from Psychoanalysis and Developmental Psychology. New York: Basic Books.

Stern, D. N. (1995). The motherhood constellation: A unified view of parent-infant psychotherapy. New York: Basic Books.

Theran, S. A., Levendosky, A. A., Bogat, G. A., \& HuthBocks, A. C. (2005). Stability and change in mothers' internal representations of their infants over time. Attachment and Human Development, 7(3), 253-268.

Van IJzendoorn, M. H. (1995). Adult attachment representations, parental responsiveness and infant attachment: A meta-analysis on the predictive validity of the Adult Attachment Interview. Psychological Bulletin, 117(3), 387403.

Vitanza, S., Vogel, L. C., \& Marshall, L. L. (1995). Distress and symptoms of posttraumatic stress disorder in abused women. Violence and Victims, 10(1), 23-34. 
Winnicott, D. W. (1987). Babies and their mothers. New York: Addison-Wesley Publishing Company, Inc.

Zeanah, C. H., \& Barton, M. L. (1989). Introduction: Internal representations and parent infant relationships. Infant Mental Health Journal, 10(3), 135-141.

Zeanah, C. H., Benoit, D., Hirshberg, L., \& Barton, M. L. (1993). Working Model of the Child Interview: Rating scales and classifications. Unpublished manuscript, New Orleans: Louisiana State University School of Medicine.

Zeanah, C. H., Benoit, D., Hirshberg, L., Barton, M. L., \& Regan, C. (1994). Mothers' representations of their infants are concordant with infant attachment classifications. Development Issues in Psychiatry and Psychology, 1, 1-14.

Zeanah, C. H., Zeanah, P. D., \& Stewart, L. K. (1990). Parents' constructions of their infants' personalities before and after birth: A descriptive study. Child Psychiatry and Human Development, 20(3), 191-206. 